\title{
EL SISTEMA DE PANÓPTICOS DE DANIEL BARROS GREZ. LITERATURA NACIONAL Y RÉGIMEN PENITENCIARIO EN CHILE EN EL UMBRAL DEL SIGLO XX
}

\author{
DANIEL BARROS GREZ'S PANOPTIC SYSTEM. NATIONAL \\ LITERATURE AND PENITENTIARY REGIME IN CHILE AT \\ THE TURN OF THE $20^{\text {TH }}$ CENTURY
}

\section{MARÍA TERESA AEDO FUENTES*}

\section{RESUMEN}

El artículo se enmarca en una indagación sobre la relación entre novela y panoptismo, discurso literario y discurso disciplinario, como rasgos que definirán a la literatura y la sociedad modernas en Chile. Propone un análisis de un ensayo del reconocido escritor Daniel Barros Grez, titulado "Utilización de los delincuentes i criminales" escrito en 1898 , en que el autor retoma el debate inaugurado en las primeras décadas del siglo por eminentes fundadores de la nación, para insistir y profundizar en el modelo panóptico como la estructura y la lógica de vigilancia más adecuada para la "domesticación humana" en Chile.

Palabras clave: Daniel Barros Grez, novela chilena siglo XIX, criminalidad, panoptismo, disciplinamiento.

\section{ABSTRACT}

This article is framed within research on the relationship between novel and panopticism, literary discourse, and disciplinary discourse as features that would define modern Chilean literature and society. It proposes the analysis of an essay by renown writer Daniel Barros Grez, entitled "Utilización de los delincuentes y criminales" (Use of delinquents and criminals) written in 1898 , where he resumes the debate started during the first decades of the 1800s by eminent founders of the nation in order to insist and deepen the panoptic model as the most adequate surveillance structure and logic for "human domestication" in Chile.

* Dra. en Literatura Latinoamericana. Profesora de la Facultad de Humanidades y Arte, Universidad de Concepción. Concepción, Chile. Correo electrónico: maaedo@udec.cl 
Keywords: Daniel Barros Grez, Chilean novel, 19th century, criminality, panopticism, discipling.

Recibido: 07.09.14. Aceptado: 06.03.15.

I

A NUMEROSA CONSTRUCCIÓn material de cárceles panópticos en toda América Latina durante el siglo XIX advierte sobre la profundidad $\checkmark y$ alcances de la incorporación del modelo panóptico de poder para construir tanto los espacios arquitectónicos como los espacios discursivos, sociales y subjetivos de las modernas repúblicas emergentes en nuestro continente.

Como hemos demostrado en un trabajo anterior ${ }^{1}$, en Chile la literatura y la penitenciaría-panóptico se concibieron desde sus comienzos como instituciones fundamentales de la nación y del orden republicano. En este marco, la presente investigación se propone analizar un texto de Daniel Barros Grez, escrito en 1898 -momento de cierre del siglo XIX y apertura del siglo XX-, en que el autor insiste y profundiza en el modelo panóptico como la estructura y la lógica de vigilancia más adecuadas para la "Utilización de los delincuentes y criminales" y la "domesticación humana” en Chile (Barros Grez, 1898, en León 1996). Este proyecto de Barros Grez se constituye en contraparte simétrica de las propuestas iniciales de los fundadores de la nación (O’Higgins, Bello, Lastarria), que a comienzos del siglo promovieron también la construcción de cárceles panópticos, debate que encuentra su expresión literaria en las novelas fundacionales de Manuel Bilbao.

Como parte de la construcción de sistemas de demarcación y transgresión social (Foucault, 1996), junto a un amplio corpus discursivo integrado por ensayos, estudios jurídicos y análisis técnicos, se desarrollará a lo largo del siglo XIX una abundante producción y circulación de textos literarios -relatos y novelas de bandidos- que contribuirán a la construcción de la figura del delincuente, predominantemente como el enemigo interno de la sociedad ${ }^{2}$. En conjunto, estos discursos trazarán los límites entre lo prohi-

${ }^{1}$ En "Panóptico, novela y sociedad modernas en Chile y America Latina: El pirata del Huayas (1855), de Manuel Bilbao" (Atenea 505, 2012, pp. 263-283), he estudiado un momento inicial del proceso de construcción de la nación independiente y de la literatura nacional en relación con los debates acerca de las mejores alternativas penitenciarias para la reclusión y rehabilitación de los delincuentes y criminales en Chile.

${ }^{2}$ Ocasionalmente, el bandido aparecerá como el pícaro o el rebelde con cuyas actitudes de burla y evasión de la vigilancia policial se identificarán ciertos grupos del "pueblo bajo". Así por ejemplo, en algunas piezas musicales, como el corrido, y en cierta literatura oral o de circulación en pliegos volantes como los de la Lira Popular, que tuvo su auge en Chile entre 1860 y 1920. 
bido y lo permitido, los espacios de inclusión, exclusión y reclusión, como categorías necesarias para instaurar el orden social y político de la nación moderna.

\section{DANIEL BARROS GREZ (1834-1904)}

Aunque es más ampliamente conocido como dramaturgo, al punto de ser considerado como uno de los fundadores del teatro chileno, Daniel Barros Grez fue también poeta, narrador, ensayista, fabulista y filólogo, además de ejercer su profesión de ingeniero y académico de la Facultad de Ciencias Físicas y Matemáticas de la Universidad de Chile.

Como dramaturgo, cultivó especialmente la comedia humorística y de costumbres en las que expresa una aguda crítica a la sociedad de la segunda mitad del siglo XIX con una intención didáctica y moralizante, así por ejemplo, en su más conocida obra, Como en Santiago, satiriza el arribismo y el afán imitador de la vida capitalina en una familia provinciana.

Como ingeniero, entre sus trabajos más conocidos se cuentan la dirección de la construcción de edificios públicos en Santiago y Curicó, la invención de un innovador sistema de regadío, el diseño de un Matadero moderno para Santiago y el proyecto de una Penitenciaría modelo para el país, proyecto en el que nos detendremos en el presente trabajo.

Ambas facetas convergen en una visión de la sociedad chilena moderna que el autor ha expresado tanto en su obra de ficción como en sus textos políticos y ensayísticos. Junto con destacar el realismo de su obra, el crítico literario Cedomil Goic anota que:

El nuevo costumbrismo tendrá una vis satírica a veces sangrienta en su crítica, que será impulsada por la entonces novedosa noción positivista, comtiana, del 'progreso'. Expresamente decía Barros Grez que su obra literaria tendía en parte "a corregir los vicios y costumbres que impiden la pronta consolidación del régimen republicano" (1954).

Como espero mostrar en lo que sigue, la fe en la idea de progreso y en la función didáctica y correctiva de la literatura tienen como base su adhesión al principio fundamental del orden, orden social y moral que requerirá la educación y el disciplinamiento del pueblo. A la vez, progreso, ley y orden republicano serán también los principios que fundamentan su propuesta de un complejo penitenciario modelo para Chile, que llevará el concepto básico del panóptico a su máxima realización.

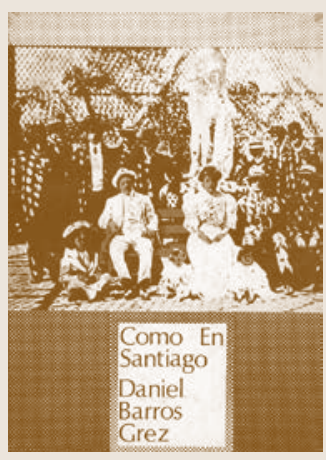




\section{LOS DELINCUENTES Y CRIMINALES DE DANIEL BARROS GREZ}

Como se sabe, a fines del siglo XIX y comienzos del XX se produce en Chile un amplio debate sobre los nuevos problemas sociales y políticos derivados del avance de los procesos de modernización e industrialización del país.

Javier Pinedo (2011) observa que, a pesar de la estabilización política y desarrollo económico alcanzado en el siglo antepasado,

Desde finales del siglo XIX, en cambio, surge una serie de pensadores que mostraban un conjunto de problemas sociales, económicos y políticos, percibidos como una muy profunda "crisis" social. Esos pensadores, denominados "aguafiestas", han pasado a la historia por sus denuncias de las divisiones sociales, de un sistema parlamentario ineficaz, de los graves problemas en materia de educación y sobre todo, de la presencia de una pobreza que no se condescendía con los afanes de modernización, a los que aspiraba un país con enormes fortunas individuales ( $\mathrm{p}$. $31)$.
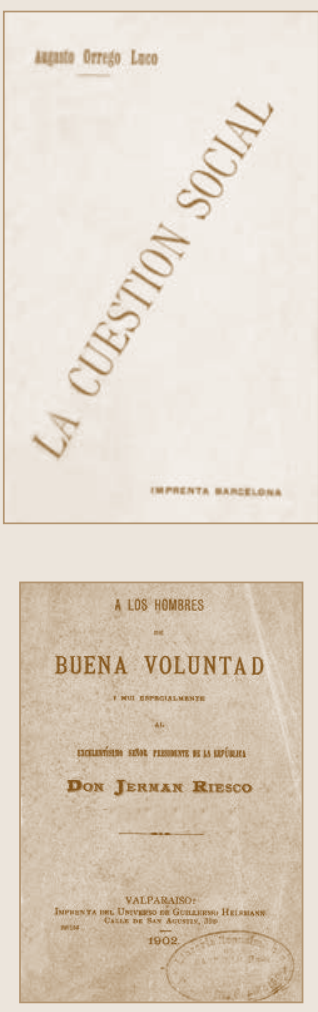

Como antecedentes de dicho debate, cabe mencionar a Augusto Orrego Luco, quien publicó en 1887 La cuestión social, donde describía la pobreza y vulnerabilidad en que vivían las familias campesinas que emigraban a las ciudades en busca de mejores condiciones laborales. Pinedo anota también como antecedentes a Arturo Alessandri, quien en 1893 publicó Habitaciones obreras; a Valentín Letelier, con Los pobres en 1896; a Juan Enrique Concha y su tesis Cuestiones obreras de 1899.

Una arista que podemos relacionar con el diagnóstico de crisis social es lo que se considera un elevado y ascendente índice de delincuencia y criminalidad. A todo lo largo del siglo XIX se había venido discutiendo cómo manejar y resolver este problema, atribuido mayoritariamente a la ignorancia e inclinaciones antisociales de individuos y grupos, a las deficiencias del sistema jurídico y a la insuficiente vigilancia policial, sobre todo en las zonas rurales, dado que los principales delitos eran los asaltos y el abigeato. Las soluciones propuestas convergían en la necesidad de fortalecer los cuerpos policiales y los sistemas legales, mejorar la oportunidad y efectividad de la acción judicial, invertir en infraestructura carcelaria y programas de rehabilitación del delincuente.

Al respecto, en 1902 Daniel Barros Grez lamenta en su ensayo A los hombres de buena voluntad. I mui especialmente al excelentísimo Sr. Presi- 
dente de la República Don Jerman Riescos, que la agricultura, "esta madre de las industrias i de todo progreso social" (Barros Grez, 1902, p. 16) no pueda prosperar debido a los numerosos asaltos de cuatreros y forajidos, situación aún más de lamentar dado que pronto se enteraría el primer siglo de vida republicana.

Particularmente proclives al delito son los "pililos propiamente dichos, esos jornaleros nómades, sin asiento fijo, i miles de ellos sin hogar, que es casi como decir sin patria. He ahí semilleros de ladrones i de enemigos de una sociedad que los considera como verdaderos parias" (p. 25). En esta sospecha radical y prejuiciada sobre la población no arraigada, no ubicable en un trabajo y espacio fijo coincide Barros Grez con los intelectuales y políticos de la época ${ }^{4}$. En el análisis de Michel Foucault es una condición social que es preciso sujetar mediante nuevas técnicas de vigilancia y control, sobre la base de una codificación de los nuevos ilegalismos (Foucault, 1996).

Barros Grez pone énfasis en que los gobiernos deben favorecer el desarrollo de la industria nacional, junto con la minería y el comercio, a fin de apoyar el progreso del país. Para ello deben actuar prontamente

tomando medidas que garanticen la seguridad personal i de la propiedad en los campos; tratando de establecer relaciones mas equitativas entre los propietarios i sus inquilinos; mejorando mas i mas la viabilidad pública; favoreciendo toda industria que pueda medrar en Chile; velando por la recta administración de justicia, sin lo cual no hai república posible; dando mas i mas impulso al desarrollo de la instrucción pública; prestando sólido apoyo a toda institución, i aun a los anhelos individuales que tiendan a mejorar las costumbres, $\mathrm{i}$ a depurar a la sociedad de los vicios que la infectan, i tratando de domesticar siquiera, a esas bandadas de jornaleros nómades que recorren las provincias, con el fin ostensible de buscar trabajo, pero también con miles [de] fines ocultos, que son otras tantas asechanzas contra la propiedad, i aun contra la vida de las jentes honradas i pacíficas (pp. 25-26).

\footnotetext{
${ }^{3}$ En esta y en todas las citas que se incluyan de las obras de Daniel Barros Grez se conservará la ortografía original de sus textos.

${ }^{4}$ Para estudios históricos sobre el tema del bandidaje en Chile véase, entre otros, los trabajos de Mario Góngora (1980), Jorge Pinto (1989), Maximiliano Salinas (1986) y Jaime Valenzuela (1991).
} 
Como puede apreciarse, el fortalecimiento o consolidación de los procesos de institucionalización de los organismos estatales se propone como una condición indispensable para la regulación social; y si bien el autor habla desde la provincia, esa institucionalización la piensa centralizada y tendiente al empadronamiento y arraigo de los habitantes para su mejor control e incorporación a las actividades laborales requeridas por el progreso industrial. No podemos dejar de destacar el término "domesticación" con el que el autor se refiere a estos procesos de normalización.

\section{“UTILIZACIÓN DE LOS DELINCUENTES Y CRIMINALES” (1898)}

Daniel Barros Grez se preocupó, en más de una ocasión, de la delincuencia y la criminalidad, a las que calificaba de "gangrenosa epidemia", "cáncer social" (Barros Grez, 1902, p. 30) y que incluyó frecuentemente como tema o episodios menores en sus obras narrativas, entre ellas Pipiolos y pelucones (1876), El huérfano (1881), Las maravillosas aventuras de Cuatro Remos (1884). El trabajo en que nos concentramos en esta oportunidad, Utilización de los delincuentes $i$ criminales, es una carta dirigida el 13 de mayo de 1898 al político y escritor Carlos Walker Martínez, que en esa fecha ejercía el cargo de ministro del Interior. La carta constituye un extracto de un estudio mucho más amplio que, según describe el mismo Barros Grez en $A$ los hombres de buena voluntad (1902), estaba escrito a dos columnas y se componía de la relación de

una serie de hechos, por orden cronolójico, de la crónica criminal de los periódicos que han llegado a mis manos, en el último cuarto del siglo pasado. En la otra columna están anotadas las observaciones referentes a dichos hechos, con el fin de deducir la mejor manera de estirpar en lo posible la criminalidad en Chile, concluyendo por describir i mostrar los medios cómo se podría llegar a construir una penitenciaria que sirviera a los criminales de escuela de aprendizaje industrial i de regeneración moral. Pero, al echar la vista sobre mi trabajo, cuando estaba para concluirse, me causó tal repugnancia, mezclada de patriótica vergüenza, que desistí de la idea de publicarlo, contentándome con dar a luz la carta aludida, que está mui lejos de decirlo todo (p. 33).

Por su parte, la carta-síntesis se proponía demostrar que

para combatir la criminalidad con esperanzas de éxito, i sacar partido, al mismo tiempo, de la intelijencia i de las fuerzas de los detenidos, me- 
jorando su condición i moralizándolos, necesitamos reunirlos a todos en una penitenciaría modelo, de la que allí hablo detenidamente. En ese lijero estudio he tratado de demostrar la ineficacia de nuestro actual sistema de prisiones, que, en jeneral, lejos de morijerar al preso, sirven para corromper mas a los principiantes... (p. 32. Destacado del autor).

Como leemos en el cierre del texto de 1902, la reclusión es para Barros Grez la medida más importante, pues la profesionalización policial resulta insuficiente por sí sola:

el único remedio radical es la combinación de una policia general en todo el pais, con una sola i única penitenciaría, que recibiendo los reos enviados por todas las prisiones secundarias de provincia, los entregue con un oficio i morijerados, según el sistema i espuesto en mi anterior opúsculo: Utilización de los delincuentes i criminales. Mientras no hagamos esto, nuestra agricultura no saldrá del estado precario en que hoi vejeta... (p. 331).

Lo que motiva su carta al ministro Walker Martínez es su preocupación ante la "desmoralización social" que percibe en la sociedad chilena y a la que contribuyen las cárceles de entonces, destinadas sólo a la reclusión, sin programas de rehabilitación de los reos; crítica en la que incluye a la penitenciaría de Santiago, pues, en su opinión profesional, esta no había sido bien construida, debido a que no se había logrado edificar como un verdadero panóptico ${ }^{5}$. En lugar de ser instituciones de re-educación moral, para evitar la reincidencia, la opinión común es que las cárceles chilenas son más bien escuelas del delito.

En el discurso de Barros Grez se despliega todo un sistema de figuración o representación del delincuente y de la criminalidad, que se pone también en funcionamiento en las obras literarias del período, de modo que se refuerza un determinado imaginario, una determinada visión, no sólo de la

\footnotetext{
${ }^{5}$ Recordemos que la construcción de la penitenciaría de Santiago se había aprobado mediante un decreto de julio de 1843 y se encontraba operativa en 1856 con 520 celdas. El entonces ministro Manuel Montt describe su diseño arquitectónico con las siguientes palabras: "El plan del edificio que el Gobierno ha considerado conveniente adoptar es el panóptico dispuesto en radios o alas partientes de un círculo central, donde estará colocada la habitación de los inspectores. Hileras de celdas, calculadas para contener a un hombre solo, ocuparán los dos lados de cada una de estas alas, i a los estremos de los patios que ellas han de dejar entre sí, deberán colocarse los talleres. Creo ser éste el plan que en más alto grado consulta la comodidad i el que más facilita la vigilancia” (Manuel Montt. Discursos, papeles de gobierno y correspondencia. Tomo II. Santiago, Chile: Imprenta Cervantes, 1905, p. 170).
} 
delincuencia, sino también de la sociedad moderna y de la república que se desea construir.

Un pilar básico de este sistema de representaciones es la contraposición entre naturaleza y cultura, de la que derivan muchas otras figuraciones. Se asocia criminalidad con descontrol de "instintos feroces", con espíritu maleado, envilecido; contraproducentemente, un pueblo salvaje castiga con crueldad, persiguiendo el sufrimiento del reo y la venganza -con lo que sólo desarrolla el odio del penado-, pero una sociedad culta y un sistema penitenciario moderno apuntan al espíritu del criminal, utilizando mecanismos para "elevar el espíritu" y "suavizar el carácter". Tal objetivo de "traer al buen camino al espíritu extraviado" (p. 267) se consigue con el trabajo y la enseñanza asociados al placer y no al martirio ni al mero lucro. Ese "buen camino" es, por cierto, "el camino del orden, la domesticación del hombre bravío" (p. 267). Como podemos notar, orden y domesticación son dos conceptos recurrentes en el discurso de Barros Grez y evidencian, sin duda, una perspectiva disciplinaria de la sociedad.

Esta idea se refuerza y amplía con el despliegue de un segundo sistema básico y reiterado de representaciones sobre la criminalidad, que la asocia con la enfermedad: esta "asquerosa enfermedad del espíritu" permite comparar a los criminales con "los enfermos de ciertos achaques contagiosos", cuya contaminación la sociedad debe prevenir y sanar. Para lograrlo, debe encerrar, aislar y aplicar castigos que sean correctivos, pero la corrección de los criminales debe ser humanitaria y cristiana para "cumplir con el gran objetivo político, social i religioso, al mismo tiempo que toda sociedad cristiana debe tener en mira de curarse a sí misma de la gangrena criminal que la corroe" (p. 267). Cárcel y hospital son, así, comparables, ambas instituciones tienen objetivos semejantes, orientados a una suerte de higienización de ciertos sujetos, y ambas existen para evitar daños derivados de una nefasta promiscuidad "tan contraria al buen orden i la disciplina" (p. 267).

Para mayor explicitación, escribe Barros Grez:

He aqui por qué decia que toda cárcel es algo como un hospital destinado a curar las enfermedades del alma, $i$ en el cual debe atenderse a la higiene del espíritu, así como en los verdaderos hospitales se atiende a la higiene del cuerpo. De otro modo, la cárcel será un lugar de infección moral, i estará muy lejos de cumplir con los dos grandes fines de curar o reformar a los culpables, preservándolos de futuras recaidas (p. 268).

Así pues, educación, policía, hospital y cárcel concurren al "gran objetivo político, social y religioso" de la salud material y espiritual de los habi- 
tantes de la república; sin embargo, ese objetivo es medio para un objetivo aun mayor que es el progreso y la prosperidad económica, vinculada a la modernización e industrialización del país.

Como veremos más adelante, se planteará también una función disciplinaria para la literatura nacional, cuanto más notable que los mismos escritores pertenecen también a los grupos que dirigen económica y políticamente a la sociedad chilena, como parte de la oligarquía y desde cargos de representación parlamentaria. De este modo, suelen ser tanto sujetos de discurso literario como sujetos de discurso político y legislativo. El mismo Daniel Barros Grez fue elegido diputado suplente por Curicó para el periodo 1861-1864.

\section{LA PRISIÓN MODELO QUE DEBERÍA SER CONSTRUIDA POR "LOS VERDADEROS PATRIOTAS"}

En demostración de que son "verdaderos patriotas", los gobernantes chilenos no deberían escatimar recursos para defenderse contra el "gran enemigo interior, que se llama vicio, crimen, ataque contra la propiedad, desmoralización pública, desconocimiento de la lei, desprecio de los mas santos principios, perturbación del orden público, i eterno estorbo de la marcha de la nacion hacia sus altos destinos" (Barros Grez, 1898, p. 269).

Debe erigirse, por lo tanto, la cárcel modelo que nuestro país necesita para cumplir con "su verdadero fin social" (p. 268); una que cuente

con todas las condiciones de seguridad, capacidad i buena distribución interior exijidas por la constante vijilancia, la saludable energía i prontitud en los castigos, exentos de toda crueldad innecesaria; la facilidad del servicio, la enseñanza de diversos oficios i el buen orden que alli debe reinar $[\ldots]$ prisiones perfeccionadas, remedio de los vicios, morijeradoras de los criminales, humanizadoras y educadoras del pueblo, reformadoras de las malas costumbres i constantes mantenedoras del orden público (p. 268).

Esa prisión modelo es, según Barros Grez, una única gran penitenciaría central, ubicada incluso geográficamente en un lugar al centro del país -en las cercanías de Chillán-, que por ser única ahorrará gastos y simplificará su administración, y asegurará "unidad de medios, de modos de obrar y de fines" (p. 265), a fin de hacerla más manejable de la gran diversidad de prisioneros y heterogeneidad de procedimientos utilizados hasta entonces 
en las diferentes prisiones. Principio y deseo de homogeneidad que es totalmente compatible con el de centralización y orden.

La propuesta concreta de Daniel Barros Grez, de la que adjunta incluso un croquis para su mejor comprensión y difusión, es el diseño de un gran sistema de panópticos, esto es, tres panópticos concéntricos construidos en un extenso terreno de 250 a 300 cuadras, esto es, 422 a 510 hectáreas o 4,225,1 kilómetros cuadrados $^{6}$. En el centro de este terreno se construiría un edificio poligonal desde cuyo centro, a su vez, se

irradian nueve galerias de celdas hácia los vértices. Las prisiones así dispuestas (llamadas panópticos, porque desde un solo punto de vista central, se las puede vijilar fácil, cómoda i prontamente) presentan inapreciables ventajas de seguridad y orden en el servicio. En el centro $a$ se eleva una torrecilla redonda, que sirve de observatorio general; i desde alli pueden vijilarse constantemente, i solo con dar unos pocos pasos, todas las puertas de las celdas, los guardianes de los corredores interiores de las galerias, los patios triangulares en donde se instalarán los talleres, etc. Para ello, bastan pequeñas torneras abiertas en los muros de la torre central.

El último piso de la torre central, $a$, será bastante elevado para establecer alli un vijia, que ausiliado de un buen anteojo, pueda ver lo que pasa hasta en los sitios mas retirados del Establecimiento (271-272).

El muro de circunvalación de este "panóptico central" contiene garitas de vigilancia comunicadas entre sí por un camino sobre el muro, que permite "andar por allí a los soldados sin ser vistos, i hacer fuego, en caso necesario, ya hácia adentro, ya hácia afuera del panóptico central” (p. 272), que se encuentra en todo momento bajo la vigilancia de la torre central. Este muro va acompañado por un camino de comunicación con el eje central y

se halla rodeado de un edificio poligonal concéntrico con el muro del panóptico interior, i forma parte de cuatro prisiones de segundo orden [...] cada uno de estos departamentos es un panóptico, cuyo punto de observación se halla donde concurren los cuatro cañones de edificios (o de celdas) de que se compone (p. 272).

\footnotetext{
${ }^{6}$ Como antigua medida de superficie, utilizada en América especialmente en Uruguay y Argentina, la cuadra cuadrada equivale a 1,69 hectáreas (Véase Álvarez, 1929).
} 
Un nuevo muro y camino de circunvalación separa estos dos panópticos de otro más "de tercer orden [...] Estos son los ocho departamentos [...] dispuestos también sobre un polígono concéntrico con los anteriores" (p. 272). Demás está decir que los muros de separación entre panópticos son "sólidos muros de cal y ladrillos" (p. 272). Los reos y los abastecimientos ingresan al centro de este sistema de panópticos por ferrocarril y son distribuidos luego en el nivel que corresponda mediante un ascensor que comunica todos los pisos entre sí; este ferrocarril "de entrada" enlaza en el exterior con el ferrocarril del sur que conecta con el resto del país. A su vez, en paralelo con los caminos de circunvalación, existe una doble vía ferroviaria que ampalma con el ferrocarril de entrada para facilitar la distribución interna de productos en el extenso espacio que ocupan los panópticos. Se proyecta así una verdadera ciudadela penitenciaria de alta seguridad.

En total, la capacidad de este sistema de panópticos es de 2.984 celdas, ampliable, de las cuales 504 corresponden al panóptico central, 1.200 al segundo y 1.280 al tercer panóptico.

Este diseño, que lleva el panoptismo a su máxima expresión, no obedece sólo a razones de seguridad, sino que es funcional también al sistema de "clasificacion i separacion de presos exijidas por el buen orden" (p. 273) y al sistema de premios y castigos que se aplicará a los reclusos, de modo que en el panóptico central quedarían encerrados los presos de más alta peligrosidad y condenados a cadena perpetua, además de los temporalmente aislados y, probablemente, los reincidentes contumaces; en el panóptico de segundo orden se alojarían los criminales condenados a menor tiempo; y en el de tercer orden se albergarían los simples delincuentes, destinando uno o dos patios a los delincuentes jóvenes y de menor edad. En los tres panópticos hay patios y talleres para trabajo, en aislamiento o colectivos, que forman parte de un programa de rehabilitación y de incentivos, pues el fruto de los productos comercializados en ellos se depositaría en una cuenta personal y se le entregaría a cada presidiario cuando haya terminado su condena, para que pueda iniciar en el exterior una vida normal -normalizada- y sustentada en el trabajo. Así como vayan mostrando buena conducta, los presos encerrados en el panóptico central podrán hacerse merecedores de una celda en el panóptico externo siguiente, que tiene más espacio y más libertad de desplazamientos y, desde éste, podrá premiársele sacándolo hacia el panóptico de tercer orden, mucho más amplio y que incluso tiene pequeños terrenos de huertas que los presos pueden cultivar en exclusiva para su provecho personal, aumentando el capital que pueden ir ahorrando para el momento de dejar la prisión. Del mismo modo y a la 
inversa, existe la posibilidad de castigar los malos comportamientos, haciendo pasar a los reos desde los panópticos externos hacia los interiores, donde las condiciones de vida son cada vez más estrictas, las posibilidades de trabajo más restringidas y los espacios más estrechos y aislados.

Luego de describir el plano y funcionamiento del sistema de panópticos propuesto, Barros Grez pasa a desarrollar una larga lista de 17 grandes ventajas de esta prisión modelo, derivadas la mayoría de la facilidad y eficiencia administrativa de una prisión única, centralizada, así como del ahorro de tiempo y dinero que significaría, lo que incluye un mejor aprovechamiento o "utilización" de las habilidades y fuerza laboral de los reclusos, con la que se puede contar incluso para construir el mismo edificio. Como una ventaja administrativa importante, Barros Grez menciona lo expedito, detallado y exacto que resultaría llevar el registro estadístico de la criminalidad. Junto con ello, sería posible instalar una moderna oficina de filiación antropométrica siguiendo el nuevo sistema implementado por Alphonse Bertillon, para identificar con certeza a los criminales, estudiar sus tendencias delictuales y registrar sus reincidencias 7 . Se facilitaría también la educación moral e intelectual de los presos y su instrucción religiosa, que se consideraba

\footnotetext{
${ }^{7}$ El método de filiación antropométrica fue propuesto en la década de 1880 en Francia por el médico y antropólogo Alphonse Bertillon y pronto fue adoptado por otras policías europeas, pues significaba una efectiva herramienta para identificar a los delincuentes. Se basaba en registrar 11 medidas corporales invariables con la edad luego de los 20 años, complementadas por tipologías de formas y datos cromáticos de partes del rostro, retrato hablado y fotografía de frente y perfil. Además de la descripción, el método contemplaba la clasificación de esta información en fichas que permitían acceder rápidamente a los registros policiales e identificar a los reincidentes. De acuerdo con Palacios, el bertillonage fue conocido en Chile desde 1892 a través de la Revista Forense Chilena; luego, en 1894, el Dr. Augusto Orrego Luco, psiquiatra y médico-legalista que había publicado en 1887 La cuestión social, comisionó al Dr. Pedro Barros Ovalle para viajar a Francia a estudiar el método de Bertillon y divulgarlo en Chile, donde editó un Manual para uso de este sistema en 1900 (Cristian Palacios. "Entre Bertillon y Vucetich: las tecnologías de identificación policial. Santiago de Chile, 1893-1924". Historia y Justicia $\mathrm{N}^{\circ}$ 1, 2013, pp. 1-28). El Manual lleva por título Manual de antropometría criminal $i$ jeneral escrito según el sistema de A. Bertillon para la identificación personal i destinado al uso de los establecimientos penitenciarios, autoridades judiciales, compañias de seguros, cuerpos armados, etc., etc. En su Introducción Barros Ovalle recomienda la aplicación obligatoria de este sistema para identificar a todos los individuos vagos y ociosos a fin de "prevenir i castigar la vagancia" por ser éste el "elemento que proporciona mayor continjente a la criminalidad" (Barros Ovalle, 1900, p. IV). Quiero destacar que el autor sugiere otra importante medida para el control de la población criminal y general: "la adopción de papeletas, o de libretas como en Suiza y otros países europeos [...] espedidas por autoridad competente, en la cual debe constar el estado civil, militar, relaciones i filiacion del sujeto, etc. [...] Todo individuo debe estar provisto de ese documento que debe exhibir a requisicion de la policia o en cualquier otro acto judicial o administrativo. La posesion de él es un justificativo de honradez i de ocupacion conocidas i su carencia una sospecha de delincuencia" (Barros Ovalle, 1900, p. $\mathrm{V})$. Encontramos aquí el origen de nuestra actual cédula de identidad.
} 
tan importante en la época, por lo que muchos atribuían el aumento de la criminalidad al abandono de la enseñanza religiosa en la educación formal. Propone, asimismo, que la instrucción primaria sea obligatoria en este establecimiento penal, al punto que se condicione la libertad de los presos aun luego de haber cumplido su condena, a saber leer, escribir y realizar las cuatro operaciones matemáticas básicas, pues también se considera que una de las principales causas de la delincuencia es la ignorancia.

Una sugerencia que llama la atención en la propuesta de Barros Grez, aunque resulta totalmente coherente como práctica disciplinaria, es su idea de "rejimentar militarmente" a los encarcelados, pues en su opinión la "militarización de los presos" (p. 278) -con excepción de los recluidos en el panóptico central-, asignándoles grados y jerarquías pondría un dique de contención a los "espíritus díscolos", en la convicción que "una disciplina estricta enjendra siempre hábitos de órden" (p. 278). Advierte, eso sí, que la dificultad que entraña la disciplina militar es que funciona según un enérgico sistema de sanciones para lograr el indispensable respeto a la reglas, lo que podría resultar contraproducente aplicado a reos que tienden a sentir su prisión como una venganza de parte de la sociedad y pudiera fomentar su odio a la misma. Para controlar y moderar este riesgo, habrá que poner el máximo esfuerzo en hacerle comprender a cada uno que

esa sociedad que él mira de reojo, es mejor que él, mas humana i mas benigna que él, i que, si le ha quitado su libertad, es solo en defensa del derecho, i con el fin de defenderlo a él mismo de sus malas pasiones, [...] Por mas recalcitrante que sea el espiritu de los criminales, pocos seran los que, tarde o temprano, no sientan despertarse en ellos los sentimientos de justicia, de órden, de bien parecer i de sociabilidad, desde que comprendan el paternal interes que la sociedad toma por su rejeneracion (p. 279).

Más allá de que en estas afirmaciones se desatiende completamente las causas sociales, políticas y económicas de la criminalidad, que el mismo Barros Grez menciona en A los hombres de buena voluntad ${ }^{8}$, estas afirmacio-

\footnotetext{
${ }^{8}$ Barros Grez resume las vergonzosas condiciones sociales que describe en la primera parte de este texto diciendo: "La corrupción social de nuestro pueblo bajo es debida en gran parte al mal ejemplo, a las insinuaciones desordenadas e ilegales, al comercio escandaloso de sufrajios i demás abusos electorales; a la presión e injusticias de que las clases inferiores han sido víctimas de parte de las superiores, i mui especialmente a nuestras detestables prisiones propagadoras de vicios, i a la falta de prontitud en el castigo de los delitos i crímenes, prontitud sin la cual no se espere jamás eficacia en los castigos" (Barros Grez, 1902, p. 22).
} 
nes aluden al objetivo final de interiorización de la norma que se pretende lograr con las tecnologías de vigilancia y reeducación.

Aquí es donde cobra toda su importancia y sentido el sistema de estímulos dado por el reconocimiento de los cambios positivos de conducta -es decir, de docilidad a las normas y dedicación al trabajo-, que le permitiría a los presos pasar "de panóptico en panóptico" (p. 279), desde el interior al exterior, dando ejemplo saludable para el espíritu de todos por el trato más blando y humano que irían recibiendo cada vez o, por el contrario, ejemplificando la sanción inhibidora de conductas desordenadas o turbulentas cuando el paso es desde los exteriores al panóptico central. Además, el autor asegura que un sistema como el que propone combatirá el pesimismo popular, pues los presos comprobarán los beneficios del trabajo y la vida útil y ordenada; la sociedad, por su parte, combatirá radicalmente los daños causados por la ociosidad de "jentes que por no trabajar, se han convertido en eternos enemigos de la propiedad i del órden público” (p. 281).

\section{LITERATURA, DISCIPLINA Y SOCIEDAD EN DANIEL BARROS GREZ}

En varias ocasiones Barros Grez explicitó su manera de comprender la literatura y su función en la sociedad. En el marco de un concepto de literatura como Bellas Letras, le concede una función didáctica y orientadora de los procesos sociales e históricos. Se trataría de una función trascendente, una "misión" sagrada a la que profesa una profunda fe como elemento civilizador, como factor de progreso y de elevación del espíritu, a la vez que como expresión de la sociedad y modeladora de las inquietudes colectivas.

Así, por ejemplo, en su "Advertencia preliminar" a su novela Pipiolos y Pelucones. Tradiciones de ahora cuarenta años de 1876, Barros Grez expresa:

Estoi íntimamente convencido, no diré de la utilidad de las Bellas Letras, sino aun mas, de la necesidad que todo pueblo tiene de cultivar su literatura; pues de otro modo, no adquirirá jamas la independencia de espíritu que ha menester para adelantar por sí mismo en el camino de la civilización. [...]Los esfuerzos hechos por la industria i el arte son poderosísimos ejemplos que, presentados oportuna i convenientemente ante los ojos del pueblo, por la literatura, lo incitan a imitar lo que es bueno $[\ldots]$

Yo no concibo otro elemento mas eficaz para desarrollar aquellos sentimientos, que una literatura propia, fundada en la naturaleza de las cosas; que ilustre i eleve el espiritu del pueblo, creando en su alma la necesidad de pensar; que pinte sus goces i sufrimientos; que trasluzca 
sus justas aspiraciones, i que retrate sus costumbres i su manera de ser; ya cantando sus glorias; ya llorando sus desaciertos, a fin de que sirvan de leccion para el porvenir (pp. 9-10).

En su "Dedicatoria” a sus Fábulas orijinales de 1888 reitera:

Creo en lo sagrado de la misión literaria; tengo una fé profunda en la eficacia de este fecundo elemento de progreso, i estoi ademas convencido de que la literatura, como expresion social, no solo debe retratar el pasado histórico i pintar el modo de ser actual, dando testimonio de la vitalidad de un pueblo, sino que, ademas, debe transparentarse también en ella el porvenir, expresando todas las esperanzas i dando forma a todas las nobles aspiraciones civiles, políticas i relijiosas de la sociedad (Barros Grez, 1888, pp. 3-4).

No pueden faltar, pues, a las Bellas Letras nacionales "esas aspiraciones al progreso material, moral e intelectual de la nación" (Barros Grez, 1888, p. 4), de modo que ella se constituye en una guía o "antorcha que alumbra", "columna de fuego" que muestra el camino del espíritu humano hacia el bien, como conducto que es "por donde el cielo hace caer las grandes i nobles ideas sobre la tierra" (Idem., pp. 4, 5).

Literatura y nación están así estrechamente ligadas, se nutren y fortalecen mutuamente, de allí que uno de los géneros cultivados por Barros Grez sea la novela histórica y que resalte el valor de la verosimilitud para las situaciones y personajes de su prosa. La literatura nacional, específicamente, debe contribuir a la construcción del orden republicano:

Porque, como queda indicado antes, cada asunto tiene sus inconvenientes propios que no pueden evitarse por completo sin desnaturalizar el asunto mismo, el cual es en el caso presente, las costumbres políticas, a una con las prácticas i usos puramente civiles.

Se ha tratado de pintar las costumbres sociales de una época de transición en que Chile pugnaba, como pugna todavía por constituirse bajo el sistema republicano, sistema por el cual acababa de pelear en los campos de batalla (Barros Grez, 1876, p. 6).

Así lo reconocen también sus contemporáneos, en relación, por ejemplo, a su novela La academia político-literaria de 1890, cuyo editor, S.M.G. Somavía, afirma en su Prólogo que para los lectores será una "lectura tan útil como sabrosa y entretenida, solazando el espíritu lo mejora, porque lo instruye, y lo eleva porque le muestra el ideal de lo bueno en el campo

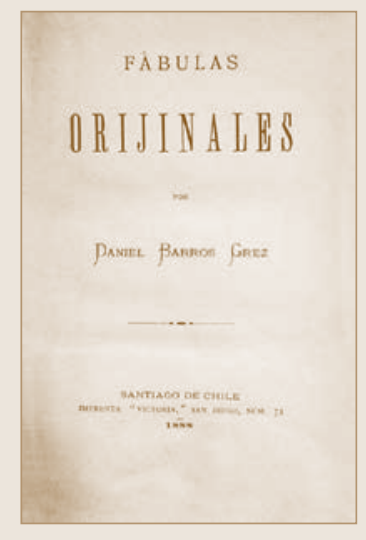




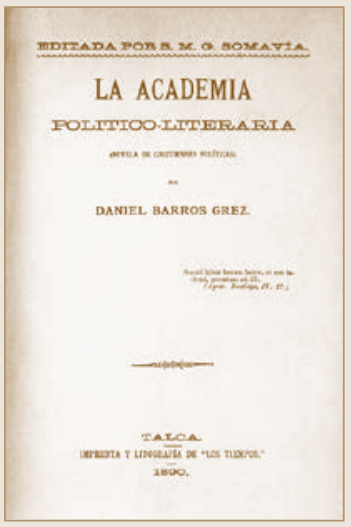

político-social, que es el verdadero campo de acción de los pueblos republicanos" (Barros Grez, 1890, p. III).

Como expresión de la sociedad, la literatura debe esforzarse por conocerla bien, y para ello el autor debe estudiarla atenta y concienzudamente desde diversos puntos de vista y hasta en sus más pequeños detalles

No es posible conocer una sociedad, sino estudiándola bajo todas sus faces, no olvidando a veces ni aun los pequeños detalles, pues suele acontecer que los detalles ínfimos, son los que mas bien marcan e iluminan la fisonomía social de una época. Esto es lo que se ha tratado de hacer (Barros Grez, 1876, p. 6).

Es una observación minuciosa a la manera de una vigilancia panorámica permanente, como lo insinúa el calificativo de "centinela" que le asigna Barros Grez a la misión superior de la literatura nacional: "Centinela avanzado del progreso, ella [la literatura] debe ir siempre a vanguardia i cernerse, graciosa i lijera, sobre nuestras cabezas, [...] (Barros Grez, 1888, p. 5). Imagen que remite a otra, referida en su novela La academia políticoliteraria a la relación entre el gobierno y el pueblo: "Es muy difícil que esto suceda [que el pueblo traspase sus derechos], cuando el pueblo obra en libertad y bajo la vigilancia de un Gobierno que con su ejemplo enseña a respetar las leyes" (Barros Grez, 1890, pp. 668-669). Parafraseando el lenguaje penal, diríamos que lo que se propone como condición ideal tanto para lectores como para ciudadanos es una suerte de libertad vigilada. ¿Será posible liberarlos en algún momento de esta paternal tutela? Como podemos observar, la vinculación de sus narraciones con el tema de la delincuencia y lo penitenciario no se da solamente por las situaciones narradas y la frecuente aparición de personajes de bandidos en los relatos de Daniel Barros Grez, sino que ambas se explican por la misma lógica y realizan en sus respectivos campos funciones semejantes. La tarea principal de la literatura nacional de vigilancia permanente del cuerpo social desde un lugar privilegiado, iluminando con atención cada detalle, por mínimo que sea, para evitar desviaciones del camino del orden, remite de inmediato a las funciones y ventajas que el mismo Barros Grez enfatiza para el panóptico total que diseña, cuyo plano ofrece a las autoridades políticas como un servicio a la república de la misma manera que ofrece sus reflexiones y creaciones literarias a los críticos y lectores.

Pero además, literatura y penitenciaría-panóptico comparten la misma función disciplinaria, como explicita el autor en varias oportunidades: 
Ademas del fin antedicho, esta novela tiene otros de no menos utilidad practica [...] Por un lado, el deseo de popularizar esta parte, la mas importante de la historia contemporánea de Chile, por las enseñanzas que envuelve; i por otro, la conviccion de que el cultivo de las Bellas Letras, es un poderosísimo elemento de morijeracion social; [...] (Barros Grez, 1876, p. 9)

De aquí la necesidad de conservar como un inapreciable tesoro, la belleza, pureza, verdad i elevacion literarias, a fin de que las Bellas Letras cumplan con su mision rejeneradora (Barros Grez, 1888, p. 5).

Se percibe incluso en esta literatura una función terapéutica semejante a la de la penitenciaría-hospital, como observa el prologuista de La academia político-literaria, destacando que este "es un libro de gran enseñanza social y de la mas pura doctrina republicana. Con tan amena lectura, el pueblo beberá esa doctrina, sin apercibirse; pues el señor Barros Grez ha sabido poner miel en el borde del vaso que contiene la medicina" (Barros Grez, 1890, p. III).

Cabe comentar en este punto, que en varias de sus obras de ficción el autor desarrolla las ideas que propone en sus ensayos y cartas respecto de la criminalidad. Así, por ejemplo, en la novela Pipiolos i pelucones en el Capítulo XLVIII, "La ejecución”, retoma el tema de la pena de muerte a propósito de una escena de ajusticiamiento público de unos bandidos vinculados al famoso Miguel Turra ${ }^{9}$, insertándola en el debate presente poniendo de epígrafe para este capítulo un fragmento de la argumentación a favor de la abolición de la pena capital realizada por José Manuel Balmaceda en 1871. El personaje portavoz del autor compara la delincuencia con una enfermedad epidémica que la sociedad tiene el deber de solucionar:

El crimen es una enfermedad social, una epidemia moral que la sociedad tiene el deber de combatir no exterminando a los enfermos, sino curándolos; es decir, ilustrando su entendimiento i enseñándolos a ser hombres de bien, i amigos del trabajo. Si la sociedad no obra de este modo, será mas o ménos responsable de los crímenes que se cometa, así como lo es de las epidemias que nacen i se desarrollan a causa de la indolencia pública (Barros Grez, 1876, p. 290).

Esta confianza en la capacidad rehabilitadora del régimen penitenciario contrasta con la descripción de los delincuentes que aparecen en sus rela-

\footnotetext{
${ }^{9}$ Elvira Dantel (1935) comenta que Miguel Turra habría pertenecido a la famosa "partida del alba”, montonera surgida en la región de Curicó y que actuó entre 1829 y 1830, en medio de los enfrentamientos entre liberales y conservadores.
} 
tos, a quienes caracteriza siempre como irracionales, violentos y con rasgos animalescos. Es el caso, por ejemplo, de los compañeros del bandido Miguel Turra: "el Vizco, cuya malignidad parecia buscar un objeto en que cebarse" (Idem., p. 286), "el maligno muchacho saltó con lijereza sobre el pavimento de la calle, i [...] se fué arrastrando como un gato" (Idem., p. 287), y del mismo Miguel Turra: "respondió Miguel con cierta sonricilla falsa que velaba su móvil semblante, siempre que no se hallaba dominado por las pasiones brutales i sangrientas, que formaban el fondo de su carácter" (Idem., p. 128), “Con su puñal en la mano, sediento de venganza, i lanzando al aire horribles maldiciones, corria aquel hombre como un perro rabioso dispuesto a morder al primero que encontrase. Parecia una fiera escapada de su jaula de hierro" (Idem., p. 177). No obstante, la plena confianza en los métodos de disciplinamiento de las conductas de los reos supera todas las dudas y apreheniones que pudieran inspirar tales naturalezas degradadas. Barros Grez asegura que "solo un carácter feroz i brutal podrá resistir a tales medios de domesticacion humana” (1898, p. 280).

\section{CONSIDERACIONES FINALES}

Desde los momentos inaugurales de la nueva nación independiente ambas instituciones - penitenciaría y literatura nacional- se concibieron como instituciones fundamentales de la nación moderna y fueron pensadas en gran parte por los mismos sujetos, que desarrollaban a la vez una actividad literaria y una actividad política.

En el recorrido que hemos realizado por los escritos de Daniel Barros Grez, he querido mostrar otro aspecto del carácter disciplinario de la novela moderna en Chile: hasta qué punto la conceptualización de la novela nacional por escritores reconocidos hasta hoy como fundadores de las letras chilenas se sustenta en un mismo tipo de pensamiento, en un mismo "sistema de racionalidad" (Foucault, 1993) que la penitenciaría-panóptico. Como observa Josefina Ludmer (1999) parafraseando a Foucault, la historia de la novela no puede entenderse separada de la historia del Estado (54). La densa red de discursos, tanto políticos como ficcionales, producida en Chile a lo largo del siglo XIX forma parte de la serie de racionalizaciones elaboradas para legitimar los sistemas de inclusión y exclusión constitutivos del orden republicano y de las estrategias que incluyen para mejor excluir a determinados sujetos sociales.

Profundizar la investigación sobre estas redes discursivas y sus transformaciones permitirá, como propone Trinidad Fernández (1989), indagar en 
los procesos de producción de una serie de saberes que tienen el efecto de la naturalizar las diferencias y consolidar los sistemas culturales de representación y de creencias, pero cuya génesis se encuentra vinculada con ciertos compromisos políticos de defensa de los regímenes de propiedad, de las leyes y de los organismos de seguridad que los protegen.

Cabe recordar con Foucault que "la disciplina es el procedimiento técnico unitario por el cual la fuerza del cuerpo está con el menor gasto reducida como fuerza política y maximizada como fuerza útil" (1993, p. 224). Desde el punto de vista de Ludmer, en nuestro ámbito cultural latinoamericano los relatos centrados en los delitos cuentan tanto la lucha por el poder literario como la lucha por el poder estatal (Ludmer 1999: 468). Ad portas del siglo XX Daniel Barros Grez refuerza la concepción de la literatura como tecnología disciplinaria que pretende normalizar para la nueva época los deseos transgresores y constituirse en recinto ficticio de disciplinamiento destinado a formar cuerpos dóciles, útiles y productivos (Rodríguez y Triviños, 2006). Aún hoy esta lucha por y entre el poder literario y el poder estatal permanece abierta para nosotros y nos inquieta preguntarnos: si estas tecnologías de control y normalización atraviesan tan profundamente todos los espacios sociales ¿es posible que alguien, en algún lugar, habite realmente fuera del sistema de panópticos descrito por Barros Grez o pueda evitar ir pasando simplemente "de panóptico en panóptico" a lo largo de su vida, como determina la lógica disciplinaria que aún sostiene nuestras sociedades?

\section{REFERENCIAS}

Aedo Fuentes, M. T. (2012). "Panóptico, novela y sociedad modernas en Chile y America Latina: El pirata del Huayas (1855), de Manuel Bilbao". Atenea, 505, 263-283.

Álvarez, J. (1929). Temas de historia económica argentina. Buenos Aires: El Ateneo.

Barros Grez, D. (1876). Pipiolos y pelucones. Tradiciones de ahora cuarenta años. Santiago: Imprenta de La Esperanza. . (1888). Fábulas originales. Santiago: Imprenta Victoria. . (1890). La academia político-literaria. Edit. por S. M. G. Somavía. Talca: Imprenta y Litografía de "Los Tiempos".

. (1898). "Utilización de los delincuentes i criminales". En: León, M. A. (1996). Sistema carcelario en Chile. Visiones, realidades y proyectos (18161916). Santiago, Chile: Ediciones de la Dirección de Bibliotecas, Archivos y Museos. 
. (1902). A los hombres de buena voluntad. I mui especialmente al excelentísimo Sr. Presidente de la República Don Jerman Riesco. Valparaíso: Imprenta del Universo de Guillermo Helfmann.

Barros Ovalle, P. (1900). Manual de antropometría criminal i jeneral escrito según el sistema de A. Bertillon para la identificación personal $i$ destinado al uso de los establecimientos penitenciarios, autoridades judiciales, compañías de seguros, cuerpos armados, etc., etc. Santiago, Chile: Imprenta de Enrique Blanchard-Chessi.

Dantel, E. (1935). "El bandido en la literatura chilena”. Boletín de la Academia Chilena de la Historia 6, 241-301.

Foucault, Michel. (1993). Vigilar y castigar. El nacimiento de la prisión. México: Siglo XXI.

. (1996). La vida de los hombres infames. Buenos Aires: Editorial Altamira.

Goic, C. (1954). "El teatro costumbrista de Daniel Barros Grez". Conferencia en el Teatro Antonio Varas el 29 de diciembre de 1954 con celebraciones de la semana de Barros Grez con motivo del cincuentenario de su muerte. Recuperado de http://www.fundadoresdelteatrochileno.uchile.cl/Daniel_Barros_Grez/Articulos/Cedomil_Goic.html

Góngora, M. (1980). "Vagabundaje y sociedad fronteriza en Chile (siglos XVII a XIX”. En: Góngora, M. Estudios de historia de las ideas y de historia social. Valparaíso: Ediciones Universitarias de Valparaíso.

León, M. A. (1996). Sistema carcelario en Chile. Visiones, realidades y proyectos (1816-1916). Santiago, Chile: Ediciones de la Dirección de Bibliotecas, Archivos y Museos.

Ludmer, J. (1999). El cuerpo del delito. Un manual. Buenos Aires: Libros Perfil S.A.

Palacios Laval, C. (2013). "Entre Bertillon y Vucetich: las tecnologías de identificación policial. Santiago de Chile, 1893-1924”. Revista Historia y Justicia, 1, 1-28.

Pinedo, J. (2011). "Apuntes para un mapa intelectual de Chile durante el Centenario: 1900-1925". América sin nombre, 16, 29-40.

Pinto Rodríguez, J. (1989). "El bandolerismo en la Frontera, 1880-1920. Una aproximación al tema”. En Villalobos, S. y Pinto, J. (comps.). Araucanía. Temas de historia fronteriza (pp. 101-122). Temuco: Ediciones Universidad de la Frontera.

Rodríguez Fernández, M. y Triviños, G. (eds.). (2006). Utopía y mentira de la novela panóptica. Concepción: Editorial Universidad de Concepción.

Salinas, M. (1986). "El bandolero chileno del siglo XIX. Su imagen en la sabiduría popular". Araucaria de Chile, 36, 57-75.

Trinidad Fernández, P. (1989). "La inclusión de lo excluido: La historia de la delincuencia y de las instituciones penales". Historia Social, 4, 149-158.

Valenzuela Márquez, J. (1991). Bandidaje rural en Chile central. Curicó, 18501900. Santiago, Chile: Dirección de Biblioteca Archivos y Museos. Centro de Investigaciones Diego Barros Arana. 